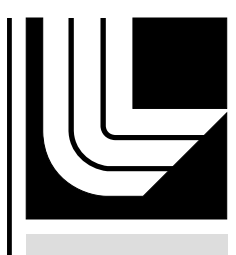

LAW RENCE LIVERMORE N A T IO N A L LABORATORY

\title{
UCRL-TR-209651
}

\section{Field Deployable DNA analyzer}

E.K. Wheeler, A.T. Christian, J. Marion, K. Sorensen, E. Arroyo, G. Vrankovich, C. Hara, C. Nguyen

February 14, 2005 
This document was prepared as an account of work sponsored by an agency of the United States Government. Neither the United States Government nor the University of California nor any of their employees, makes any warranty, express or implied, or assumes any legal liability or responsibility for the accuracy, completeness, or usefulness of any information, apparatus, product, or process disclosed, or represents that its use would not infringe privately owned rights. Reference herein to any specific commercial product, process, or service by trade name, trademark, manufacturer, or otherwise, does not necessarily constitute or imply its endorsement, recommendation, or favoring by the United States Government or the University of California. The views and opinions of authors expressed herein do not necessarily state or reflect those of the United States Government or the University of California, and shall not be used for advertising or product endorsement purposes.

This work was performed under the auspices of the U.S. Department of Energy by University of California, Lawrence Livermore National Laboratory under Contract W-7405-Eng-48. 


\title{
FY04 LDRD Final Report Field Deployable DNA analyzer LDRD Project Tracking Code: 04-ERD-074 Elizabeth Wheeler, Principal Investigator
}

\begin{abstract}
This report details the feasibility of a field deployable DNA analyzer. Steps for swabbing cells from surfaces and extracting DNA in an automatable way are presented. Since enzymatic amplification reactions are highly sensitive to environmental contamination, sample preparation is a crucial step to make an autonomous deployable instrument. We perform sample clean up and concentration in a flow through packed bed. For small initial samples, whole genome amplification is performed in the packed bed resulting in enough product for subsequent PCR amplification. In addition to DNA, which can be used to identify a subject, protein is also left behind, the analysis of which can be used to determine exposure to certain substances, such as radionuclides. Our preparative step for DNA analysis left behind the protein complement as a waste stream; we determined to learn if the proteins themselves could be analyzed in a fieldable device. We successfully developed a twostep lateral flow assay for protein analysis and demonstrate a proof of principle assay.
\end{abstract}

\section{Introduction/Background}

DNA is contained in: blood, semen, skin cells, tissue, organs, muscle, brain cells, bone, teeth, hair, saliva, mucus, perspiration, fingernails, urine, feces, etc. Only $0.1 \%$ of DNA ( $\sim 3$ million bases) differs from one person to the next. However, sufficient differences exist in this $0.1 \%$ to allow identification of individuals based on their DNA. A DNA profile is analogous to traditional fingerprint analysis. Short Tandem Repeat (STR) DNA analysis is the standard used by law enforcement agencies. Comparison of an unknown sample to an individual's STR pattern gives very high uniqueness $\left(10^{13}-10^{15}\right)$.

A small portable DNA tester, designed specifically to test DNA samples is the goal of this work. The concept has the following aspects: automated sample preparation, the device for the DNA analysis, and the PCR based analysis of DNA signatures. Our research investigates the fundamental limits of sample type, sample acquisition and analysis necessary for a field deployable human forensics identification device.

A sample of interest will be collected and input into the device. The sample from the input swab/tissue sample will then be combined with an equal volume of high-salt lysis/purification solution and passed through a lyser and into an extractor. The extractor is able to concentrate DNA into a small volume while also purifying it. After the initial adsorption from the lysis/purification solution onto the extractor, the adsorbed DNA is washed and then dried. The reaction buffer for the whole genome amplification (WGA) is then passed into the chamber where the DNA is immobilized on the surface. Amplification is performed directly on the DNA adhered to the surface. The DNA extractor is included to provide both purification and concentration. WGA and PCR are very powerful techniques, but the enzymatic reactions can be inhibited by several environmental contaminants if the sample is not purified. By performing in-situ PCR in the same concentration/purification 
chamber we will be able to amplify approximately $75 \%$ of the DNA, compared to approximately $50 \%$ that is currently available for PCR when the sample is amplified in a different chamber. Development of the purification and amplification chambers is currently being developed under the scope of a different project. This project leveraged the reaction chambers for future integration into an autonomous device.

The focus of this paper is to report on the feasibility of automating all the necessary steps and proving the whole genome amplification of DNA in the packed bed (purification and concentration chamber).

\section{Research Activities}

During this six month research project we focused on

- Sample acquisition and preparation: Isolating the cells rapidly and using a method that could be automated.

- Whole-genome amplification-WGA increases amount of DNA available for analysis, starting from just a few cells determining how quickly can we amplify DNA enough to perform analyses

- Protein analysis - In addition to the above areas which focused on analyzing DNA (answering who was present) we also devised a technique to identify what they had been doing, by analyzing proteins which were a waste stream from the DNA extraction steps. Although not included in the scope of work in the original proposal we were able to successfully demonstrate proof of principle.

\section{Results/Technical Outcome}

\section{Sample Acquisition and Preparation}

Sample acquisition from surfaces is most often performed by swabbing. To standardize the swabbing technique we developed a modified tube that essentially wrings out the swab as the user extracts it from the lysis solution. After swabbing a surface the user inserts the swab through a hole in the top of a centrifuge tube into the lysis solution (Figure 1a). The swab is then mildly agitated in the solution and the cells are removed from the swab to the lysis solution. As the swab is withdrawn through the top the inserted feature (Figure $1 b$ and $c$ ) wrings out the swab leaving more solution (containing DNA) in the tube for analysis.

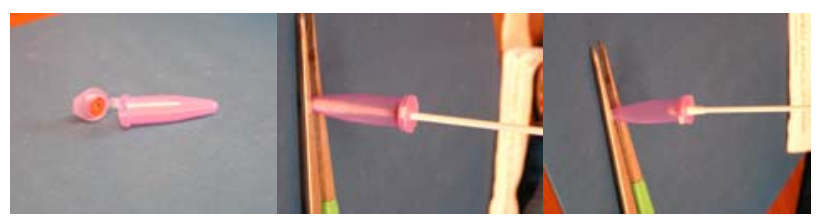

Figure 1: a) Insertion of swab with adhered DNA into lysis solution, b) Withdrawal of swab through modified tube, c) view of open tube to show foam structure to maximize solution returned to vial.

When working with small samples, sample preparation becomes highly important. Even the slightest contamination can alter the outcome of a reaction, or inhibit it altogether. Traditional methods of cleaning samples, such as organic extraction followed by ethanol precipitation, or lysing and then passing through a column are known to lose a relatively large amount of sample. This is particularly detrimental when the sample was limited in the first place. 
We present a technique that couples the use of whole genome amplification with a packed silica column. The most effective method of sample purification and extraction is to simply mix the cells once in solution using the above swabbing technique with a denaturation solution. The sample is loaded and bound to the column. While bound, the DNA is then washed and amplified, making use of all the available starting material. After amplification, the sample can be eluted for further analysis. Although some material may be lost, we demonstrate that successful PCR analysis can still be performed with as little as $20 \mathrm{pg}$ of DNA. Parallel samples in which DNA was simply washed in the column, as in traditional clean up protocols, could not be successfully analyzed.

Whole Genome Amplification

Since only small initial amounts of DNA will be present in the samples of interest whole genome amplification is necessary to increase the amount of DNA available for analysis. Before this research all phi 29 amplification was performed for 16 hours. Generating a calibration curve for amplification time involved quantifying DNA by picogreen analysis. Details of this process are given in the appendix. In summary, sufficient DNA is generated after 4 hours of amplification. Study of times shorter than four hours were not as consistent and not correlation between time and amount of DNA could be generated. For example, starting with 2ng of DNA and amplifying for just 15 minutes resulted in approximately $500 \mathrm{ng}$ of DNA.

Figure 2 below shows the successful amplification of DNA as a function of reaction time for two different initial amounts of DNA. Decreasing the reaction time from 16 hours to just 4 hours still produces sufficient DNA for subsequent analysis.
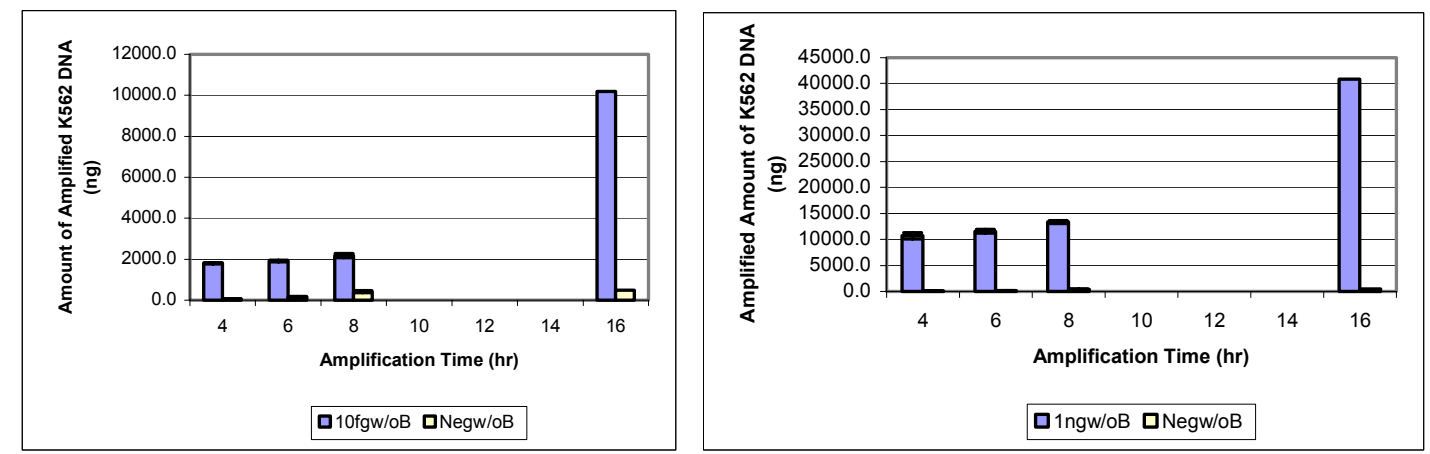

Figure 2: Calibration curve for phi 29 reaction as function of reaction time for two starting amounts of DNA. a) Initial amount of DNA is $10 \mathrm{fg}, \mathrm{b}$ ) initial amount of DNA is $1 \mathrm{ng}$.

\section{WGA in clean up column}

Initial experiments in our lab were performed using larger amounts of DNA to test the feasibility of whole genome amplification within a column. Despite the large surface area the concentration of reagents was the same as in a centrifuge tube. Some studies have found that due to the increased surface area reagents will be lost by adhesion to the surface. Amplification in a packed bed was successful. Reactions containing 5, 2 and $1 \mathrm{ng}$ of DNA produced positive Phi29 results followed by PCR $100 \%$ of the time. This set of experiments demonstrated that the packed bed is able to both purify (by removal of the chemical inhibitor guanidine isothiocyanate which is used as a denaturation solution) and concentrate the input DNA solution.

For practical applications of these methods, we are interested in much smaller initial quantities of DNA. By performing WGA of DNA bound to the silica beads in the 
column we should have a much lower limit of detection than if the DNA had to first be eluted. After verifying amplification in the presence of the silica beads, we tested the following total amounts of DNA: $0.5,0.05$ and $0.02 \mathrm{ng}$ DNA. In side by side experiments, samples were washed and amplified within the column, or washed, eluted and amplified outside of the column. DNA prepared in both fashions was then amplified by PCR. Results from this experiment are shown in Figures 3 and 4. In Figure 3, whole genome amplified samples can be seen, prepared both in and out of the column. Although results appear similar at this stage, Figure 4 shows that successful PCR analysis is much more difficult on samples that had been eluted from the column before amplification. In our experiments, we performed five PCR analyses on each quantity of DNA (since the DNA becomes diluted upon elution), but had only a $20 \%$ success rate on the highest amount of starting material and no success on the other amounts of starting material (see Table 1)

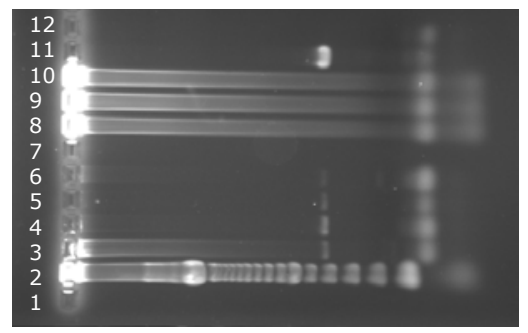

Figure 3: Gel showing positive amplification of DNA when amplified on the surface of the beads in the packed column. Lanes are: (1) Empty, (2) 100 bp ladder, (3) 50pg sample - phi29 mix flushed out of bed through frit (before eluting step), (4) 50pg sample - eluted DNA(TE heated at $72 \mathrm{C}$ for $3 \mathrm{~min}$, flushed out of bed w/beads), (5) $20 \mathrm{pg}$ sample - phi29 mix flushed out of bed through frit (before eluting step), (6) $20 \mathrm{pg}$ sample - eluted DNA(TE heated at $72 \mathrm{C}$ for $3 \mathrm{~min}$, flushed out of bed $\mathrm{w} / \mathrm{beads}$ ), (7) Empty, (8) phi29 positive control - 50pg DNA amplified via phi29 rxn in tube, (9) phi29 positive control - 20pg DNA amplified via phi29 rxn in tube, (10) phi29 negative control - H2O as "template" in phi29 rxn in tube, (11) MT-PCR positive control - stock K562 (10ng/ul) as "template" in MT-PCR recipe, (12) MT-PCR negative control - $\mathrm{H} 2 \mathrm{O}$ as "template" in MT-PCR recipe

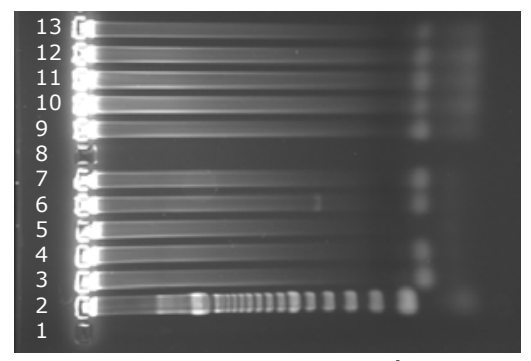

Figure 4: Agarose gel generated from eluted DNA (traditional clean up column). Lanes are: (1) Empty, (2) 100 bp ladder, (3-7) 50pg sample only PCR band in lane 6 (1 out of 5 successful PCR), (8) Empty, (9-13) 20pg sample, no successful PCR products

\begin{tabular}{|c|c|c|}
\hline & \multicolumn{2}{|c|}{ \% successful PCRs } \\
\hline Amount of DNA & Within column & External to column \\
\hline $2 \mathrm{ng}$ & 100 & 100 \\
\hline $0.5 \mathrm{ng}$ & 100 & 100 \\
\hline
\end{tabular}




\begin{tabular}{|c|c|c|}
\hline $0.05 \mathrm{ng}$ & 100 & 20 \\
\hline $0.02 \mathrm{ng}$ & 100 & 0 \\
\hline
\end{tabular}

Table 1: Comparison of limit of detection for DNA amplified in packed bed versus DNA eluted from packed bed and amplified on the benchtop (traditional clean up column) as determined by successful PCR amplifications subsequent to WGA.

These results indicate the feasibility of combining clean-up and whole genome amplification into a single step. When performed separately, much larger amounts of starting material must be used in order to compensate for significant losses during clean-up. By amplifying the sample prior to elution, these losses are no longer a problem.

This technique could prove to be very useful for forensic science applications. A great deal of effort is currently being directed at using the DNA contained in a single fingerprint. Most researchers found that a single print contains anywhere from less than $40 \mathrm{pg}$ to $2 \mathrm{ng}$. In a previous paper, we demonstrated successful amplification of this amount of material, but many samples obtained for analysis require clean up from environmental contaminants. This is easily possible given the above technique, which was successful with as little as 20 pg of DNA.

Much of law enforcement DNA analysis is performed by STR analysis. While extremely efficient when analyzing a single subject this technique typically fails when the sample contains DNA from many subjects. However, since this is the standard that law enforcement uses we will work on modifying this technique for use with multiple subjects. Alternatively Alu PCR reactions can identify a subject's ethnicity. However, more than 100 reactions are required to accomplish this. The number of reactions is far too high for this particular application, plus it is unknown whether this analysis would yield a unique identification of a single individual from a pool of subjects of the same ethnicity. Haplotypes are combinations of alleles that a population shares. Recently researchers have constructed a haplotype map of the human genome. After much research into using haplotype analysis for identification we determined that the most appropriate analysis technique for identification is still STR analysis. Several companies are investing in this area and their developments will continue to be monitored and incorporated as the technology matures.

\section{Protein analysis}

In addition to DNA, which can be used to identify a subject, protein analysis can be used to determine exposure to certain substances, such as radionuclides. Our preparative step for DNA analysis left behind the protein complement as a waste stream; we determined to learn if the proteins themselves could be analyzed in a fieldable device.

A considerable effort has been made to develop a number of diagnostic assays for protein recognition using antibody based detection mechanisms. Similar to the development of such lateral flow assay test strips found in most standard pregnancy tests we developed the use of a similar devise that would detect for proteins present in human cells as a result of a hazardous material exposure. Our model uses identifiable HeLa cells transfected with the human chorionic gonadotropin (hCG) gene that have hCG glycoprotein expression normally produced by pregnant women and can be detected through a lateral flow antibody binding pregnancy tests to confirm protein expression. Human chorionic gonadotropin (hCG) is a glycoprotein hormone produced by normal trophoblast cells of the placenta and sometimes produces by the pituitary gland. During pregnancy these hormonal levels increase and a high level of protein expression is excreted in blood and urine 
samples of the individual. This glycoprotein hormone is therefore used as a precursor to determine whether a woman is pregnant. The First Response ${ }^{\mathrm{TM}}$ pregnancy test uses an immunoassay liquid chromatography test strip to detect for greater than 15-25mIU of hCG protein levels in urine to confirm pregnancy.

Our intention is to demonstrate an effective method of cellular pickup, lysis, and lateral flow protein detection method in an easy process that could be self administered as a diagnosis tool in large scale applications for quick diagnosis of human infection and other methods of harmful agent detection in biochemical materials.

\section{Lysis of cells for protein analysis}

Several lysis solutions were tested using the least amount of human or mechanical manipulation to detect total protein concentration. No mechanical steps, such as vortexing or centrifuging were considered. Chemical lysis was the only method considered for implementation in a fieldable device. Figure 5 compares lysis efficencies of Hela cells pre-transfection for CellLytic lysis/extraction solution both with and without $5 \mathrm{mg} / \mathrm{ml}$ lysozyme. The inclusion of lysozyme in the lysis solution increased the amount of lysed proteins 3 fold, see Figure 5.

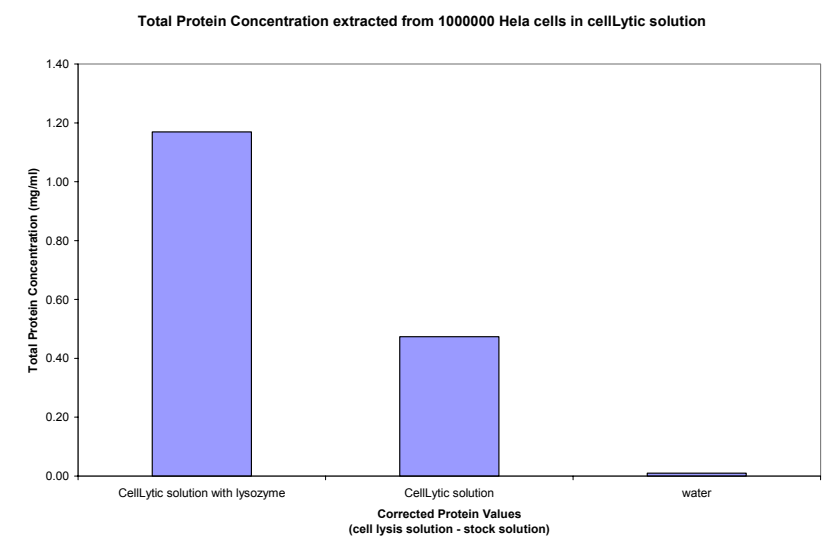

Figure 5: Cell lysis of $10^{5}$ Hela cells for total protein quantification $(\mathrm{mg} / \mathrm{ml})$ using different lysis solutions. Water was run as a control for the quantification assay.

\section{Rapid One Step Detection Assay}

We have developed a simple process for isolating cells from a surface and lysing them. This one step method allows us to swab cells off of a glass slide, insert the swab into a lysis buffer, and identify the presence of a particular protein using a lateral flow assay. To accomplish this, we engineered a human epithelial cell line that expresses the human chorionic gonadotropin protein (HCG), which is the protein tested for in lateral flow pregnancy tests. HCG cells $\left(10^{6}\right.$ cells) were dropped on cleaned microscope slides (see Appendix for details). The cells were then washed in $3 X$ PBS solution. The slides were then swabbed directly with the chromatography paper at the end of the test strip (Figure 6a).

The test strip chromatography paper was then placed in a cap containing the lysis buffer, which was quickly absorbed by the paper. The solution rapidly lyses the cells, releasing the HCG protein, which then reacts on the test strip with a total elapsed experimental time of $\sim 5$ minutes (Figure $6 \mathrm{~b}$ ).

Figure 7 shows the pregnancy test strips used for both the non-HCG-expressing swabbed cells (left) and the HCG-expressing cells (right). The arrows indicated with 
a (1) are the positive controls for the test. Although fainter for the HCG-expressing cells the control line is present for both samples, confirming that the assay is performing as expected. Arrows (2) also show a positive test line for the HCGexpressing cells (right) but no positive test line for the non-HCG-expressing cells. We quantified the level of HCG in the cells by standard ELISA assays, and found that the protein lysis protocol reacting while migrating on the chromatography paper was able to release $80 \%$ of the protein in the cells, based on the published sensitivity of the lateral flow HCG test kit that we used (Figure 7).
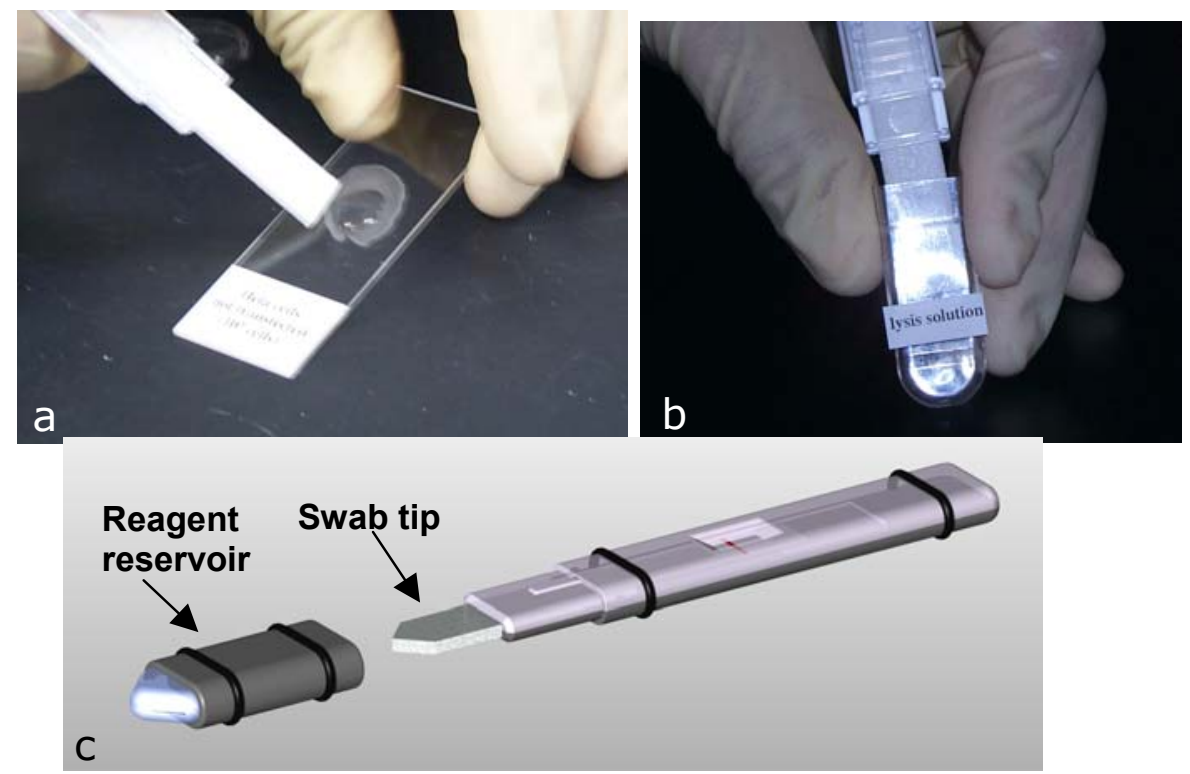

Figure 6: a) A droplet containing $10^{6}$ cells expressing HCG is swabbed from a glass slide using stiff chromatography paper. The cells adhere to the rough paper. b) The swab with cells attached is inserted in the lysis/carrier solution. The cells are lysed while the solution travels up the chromatography paper. By the time it reaches the test band, all reactions have occurred. c) Schematic of swab and lysis solution. Notch on swab tip positions swab tip for storage (pre-use) or lysis depending on orientation and alignment with reservoir.

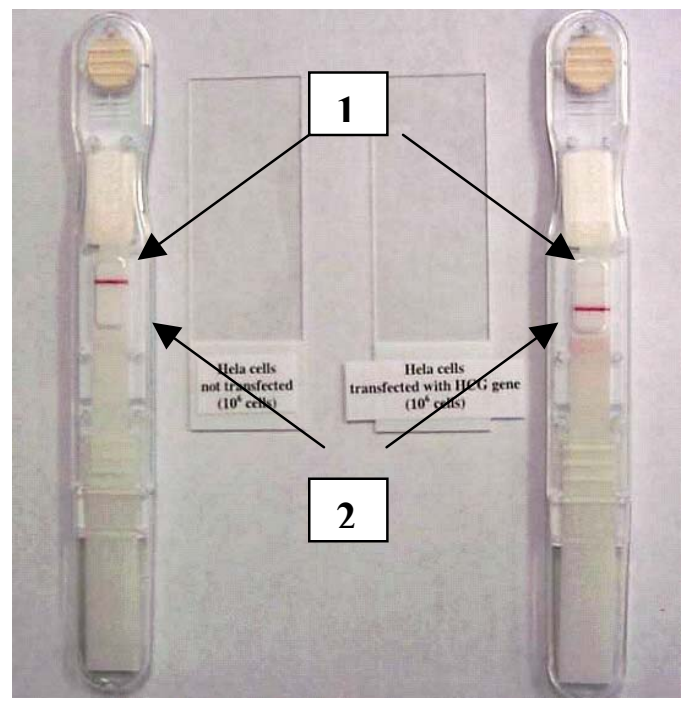


Figure 7: Pregnancy test strips with arrows showing positive control lines for both the non-HCG-expressing swabbed cells (left) and the HCG-expressing cells (right) (1). Arrows also show a positive test line for the HCG-expressing cells (right) but no positive test line for the non-HCG-expressing cells.

For both of these experiments the cells were swabbed from a microscope slide using just chromatography paper as the swab. A single lysis and reaction step was performed once the chromatography paper was inserted into the lysis reagent reservoir. By the time the solution has flowed along the chromatography paper to the test band all reactions have occurred and a positive result can easily be detected.

We have demonstrated that the notion of a simple, two-step assay is viable for the detection of exposure to biological or radiological agents. The change in expression of proteins is an easy noninvasive method when combined with lateral flow assays. Lateral flow assays are easy to use tools for first responders to assess human exposure to differing agents. Our one step method reduces a first responder's level of intervention necessary to perform a test (mechanical steps) without decreasing accuracy while providing a rapid response to help with triaging victims.

\section{Publications / Records of Invention}

This work resulted in 2 ROIs and 2 papers that are in preparation for submission to refereed journals.

\section{Exit Plan}

Various government agencies have expressed interest in our techniques and we are currently pursuing funding opportunities in this arena.

\section{Summary}

We have demonstrated that the notion of a simple, one-step assay is viable for the identification of subjects and detection of exposure to hazardous materials. Using DNA analysis a subject can be identified. Often a responder only has a very small amount of starting material ( $<10$ cells). By subjecting the DNA to our procedure to maximize DNA recovery (wringing out the swab) and performing whole genome amplification there becomes enough DNA for subsequent analyses. Whole genome amplification using phi29 has been shown by many to produce an accurate representation of the starting material, making it a viable first step in sample analysis. When performed in a column it provides a useful means of cleaning and analyzing very small amounts of DNA. We also determined that the change in expression of proteins is an easy noninvasive method when combined with lateral flow assays. Lateral flow assays are easy to use tools for first responders to assess human exposure to differing agents. Our one step method reduces a first responder's level of intervention necessary to perform a test (mechanical steps) without decreasing accuracy while providing a rapid response to help with triaging victims. 
$-11-$ 


\section{Appendix \\ Protocol for PicoGreen Quantitation}

In order to quantify the success of the MDA reaction PicoGreen analyses (Molecular Probes, Eugene, OR) were performed. To generate the curves for greater than 4 hours of amplification the following concentrations of $10 \mathrm{ng} / \mu \mathrm{L} \mathrm{K562} \mathrm{hgDNA}$ were amplified with the phi29 protocol: $10 \mathrm{fg} / \mathrm{ul}, 100 \mathrm{fg} / \mathrm{ul}, 1 \mathrm{pg} / \mathrm{ul}, 10 \mathrm{pg} / \mathrm{ul}, 100 \mathrm{pg} / \mathrm{ul}$, $1 \mathrm{ng} / \mathrm{ul}$. Each DNA concentration was amplified in a Phi29 reaction with a $154 \mu \mathrm{L}$ total volume. $25 \mu \mathrm{L}$ of DNA sample was removed from each reaction tube at the desired time point during the amplification period. The removed samples were heat denatured at $65 \mathrm{C}$ for 10 minutes and cooled to 4C. Following Phi29 protocol, PicoGreen quantitation analysis was performed.

Detection and quantitation of amplified amounts of DNA was performed using PicoGreen dsDNA quantitation reagent. The following are included in the Molecular Probes' PicoGreen dsDNA Quantitation Kit (P/N: P-11496): 20X TE (200mM Tris- $\mathrm{HCl}$, 20mM EDTA, pH 7.5) buffer; PicoGreen dsDNA quantitation reagent; Lambda DNA standard $(100 \mu \mathrm{g} / \mathrm{mL}$ in TE). $10 \mathrm{~mm} \times 10 \mathrm{~mm}$ polystyrene cuvettes from Turner Designs were used in the experiment (P/N: 7000-957). First, the 20X TE buffer was diluted 20-fold with distilled water for a final $1 X$ TE working solution. An aqueous working solution of the PicoGreen reagent was prepared by a 200 -fold dilution using $1 \mathrm{X}$ TE. This reagent was protected from light and was used within a few hours of preparation. A high range and low range standard curves were prepared from Lambda DNA in order to calculate the concentration of DNA in each sample. A $2 \mu \mathrm{g} / \mathrm{mL}$ working solution of $100 \mu \mathrm{g} / \mathrm{mL}$ Lambda DNA was prepared by a 50 -fold dilution in 1X TE. A five-point high standard curve $(1 \mu \mathrm{g} / \mathrm{mL}, 100 \mathrm{ng} / \mathrm{mL}, 10 \mathrm{ng} / \mathrm{mL}$, $1 \mathrm{ng} / \mathrm{mL}, 0 \mathrm{ng} / \mathrm{mL}$ ) was prepared by diluting the $2 \mu \mathrm{g} / \mathrm{mL}$ working solution with $1 X \mathrm{TE}$. A seven-point low standard curve $(25 \mathrm{ng} / \mathrm{mL}, 10 \mathrm{ng} / \mathrm{mL}, 2.5 \mathrm{ng} / \mathrm{mL}, 1 \mathrm{ng} / \mathrm{mL}$, $250 \mathrm{pg} / \mathrm{mL}, 25 \mathrm{pg} / \mathrm{mL}, 0 \mathrm{pg} / \mathrm{mL}$ ) was prepared by diluting the $1 \mu \mathrm{g} / \mathrm{mL}$ DNA stock solution prepared in the high standard curve with $1 \mathrm{X}$ TE. To each tube that contained a final sample volume of $1.0 \mathrm{~mL}, 1.0 \mathrm{~mL}$ of the working solution of PicoGreen reagent to make the total volume of $2.0 \mathrm{~mL}$. All tubes were mixed well and protected from the light. The sample fluorescence was measured using a Turner Designs TD-700 Fluorometer (Model \# 7000-009) at 520nm while exciting at 480nm. The fluorometer's gain was set so that the sample containing the highest DNA concentration had a fluorescence value near the fluorometer's maximum. Each standard solution was read three times and the average was calculated. The fluorescence value of the reagent blank(1X TE) was subtracted from each sample's average reading. The corrected readings were used to generate standard curves of fluorescence versus known DNA concentration. A linear relation was observed before proceeding to measuring the experimental DNA samples. The experimental DNA samples were diluted 500 -fold with 1 X TE to a final volume of $1.0 \mathrm{~mL}$. Three separate dilutions of each initial DNA concentration sample were made in order to get a more precise average fluorescence value. To each tube, $1.0 \mathrm{~mL}$ of the working solution of PicoGreen reagent was added. The fluorescence of the DNA samples was measured with the instrument calibrated to the low standard curve first. Any samples that had higher fluorescence intensity than the fluorometer's maximum for the low standard curve was measured after the instrument was calibrated to the high standard curve. The fluorescence value of the reagent blank (1X TE) from the corresponding standard curve was subtracted from each sample. The DNA concentration of the experimental samples was determined from the standard curves generated. 
hCG gene transfection into HeLa cells:

Bacterial strains, cultures, and plasmids

The $E$. coli host strain DH10B was used to grow up the pOTB7 plasmid (1815 bp) that contained the human chorionic gonadotropin (hCG) gene (\#5431911

I.M.A.G.E. Consortium/LLNL). The hCG gene beta polypeptide coding region (931 bp) had been inserted in the pOTB7 plasmid between the ECORI and XhoI restriction enzyme sites. Bacteria were grown overnight at $37^{\circ} \mathrm{C}$ on Luria-Bertani (LB) agar plates containing chloramphenicol $(100 \mu \mathrm{g} / \mathrm{ml})$, and single colonies of the overnight culture were picked and grown in $3 \mathrm{ml}$ of LB liquid media with chloramphenicol $(100 \mu \mathrm{g} / \mathrm{ml})$ for $\sim 8 \mathrm{~h}$ at $37^{\circ} \mathrm{C}$ with vigorous shaking $(250 \mathrm{rpm})$. Then $200 \mu \mathrm{l}$ of this liquid culture was used to inoculate $100 \mathrm{ml}$ of LB media with chloramphenicol $(100 \mu \mathrm{g} / \mathrm{ml})$ and was grown up overnight for $16 \mathrm{~h}$ at $37^{\circ} \mathrm{C}$ with vigorous shaking (250rpm). The pOTB7 plasmid was isolated using a QIAGEN Plasmid Purification Maxi Kit (QIAGEN, Valencia, CA) and was resuspended in $60 \mu \mathrm{l}$ TE buffer, $\mathrm{pH} 8.0$, to yield a vector DNA concentration of $6.209 \mu \mathrm{g} / \mu \mathrm{l}$.

The purified pOTB7 vector was the template used in PCR amplification of the hCG gene. Oligonucleotide primers hCGforward (5'-GCC GCC GCC ATG GAG ATG TTC CAG GGG CTG-3') and hCGreverse (5'-TTA TTG TGG GAG GAT CGG GGT GTC CG-3') were used (Sigma Genosys, The Woodlands, TX) and designed to include the KOZAK sequence to enhance hCG gene translation efficiency. The hCGF and hCGR primers were diluted to $200 \mu \mathrm{M}$ in TE buffer. The PCR mixture contained $1 \mu \mathrm{l}$ of total template DNA, $4 \mu \mathrm{M}$ of each of the primers, Buffer A (Roche, Basel, Switzerland) with $1.0 \mathrm{mM} \mathrm{MgCl} 2$ at $\mathrm{pH} 8.3,200 \mu \mathrm{M}$ of dNTP (Roche), $10 \mu$ of 1 X GC Rich Solution (Roche), and $2 \mathrm{U}$ of FastStart Taq DNA Polymerase (Roche), in a total volume of $50 \mu$ l. After a denaturation step at $95^{\circ} \mathrm{C}$ for $5 \mathrm{~min}$, PCR was run for 35 cycles at $94^{\circ} \mathrm{C}$ for $60 \mathrm{sec}$ and $60^{\circ} \mathrm{C}$ for $30 \mathrm{sec}$, followed by a final elongation step at $72^{\circ} \mathrm{C}$ for $3 \mathrm{~min}$. Samples were analyzed on $2 \%$ agarose gels with 1 X TBE buffer at $100 \mathrm{~V}$. Amplified products were purified using a QIAquick PCR Purification Kit (QIAGEN) and resuspended in $30 \mu \mathrm{l}$ of $10 \mathrm{mM}$ Tris- $\mathrm{Cl}, \mathrm{pH} 8.5$.

\section{Transformation}

The hCG gene amplified from the pOTB7 plasmid was ligated into the shuttle vector of choice, the pTargeT vector (Promega, Madison, WI). The pTargeT vector (5670 bp) had resistance to ampicillin and the antibiotic G-418, and it contained the $\beta$-galactosidase coding sequence, making blue/white screening possible. Additionally the pTargeT vector had 3'-thymidine overhangs at the hCG gene insertion site, increasing the probability of successful ligation of the hCG insert in the proper orientation. The hCG gene was ligated into the shuttle vector using the pTargeT Mammalian Expression System (Promega). The ligation reaction was carried out with $1 \mu$ l T4 DNA Ligase (3 Weiss units), $1 \mu$ l of 10X T4 DNA Ligase Buffer, 60ng of pTargeT vector, and $7 \mu \mathrm{l}$ of hCG amplified product. Control ligation reactions were also run with positive control insert DNA (542bp) and without insert DNA altogether. All samples were incubated at $4^{\circ} \mathrm{C}$ overnight.

Following the ligation of the hCG gene into the pTargeT vector and the controls, JM109 High Efficiency Competent Cells (Promega) were transformed with each of the three ligation reaction products and an uncut plasmid to measure transformation efficiency. The uncut plasmid used was the pSP72 vector with resistance to ampicillin at an amount of $1.0 \mathrm{ng}$ per $1 \mathrm{ml}$ of total transformation reaction volume. Protocol outlined by Promega was followed as mixtures of $50 \mu \mathrm{l}$ of 
JM109 cells and $2 \mu \mathrm{l}$ of ligation reaction product were iced for $20 \mathrm{~min}$, heat shocked for $45 \mathrm{sec}$ at $42^{\circ} \mathrm{C}$, and then incubated in $950 \mu \mathrm{l}$ of SOC medium, pH 7.0, for 1.5 hours at $37^{\circ} \mathrm{C}$ with shaking ( $\left.200 \mathrm{rpm}\right)$. Then $100 \mu$ l of each transformation reaction was plated on duplicate antibiotic plates. LB plates were used with ampicillin $(100 \mu \mathrm{g} / \mathrm{ml})$, and $100 \mu \mathrm{l}$ of $100 \mathrm{mM}$ IPTG and $20 \mu \mathrm{l}$ of $50 \mathrm{mg} / \mathrm{ml} \mathrm{X-Gal} \mathrm{were} \mathrm{added} \mathrm{topically} \mathrm{to} \mathrm{the}$ plates. The IPTG and X-Gal were allowed to absorb into the LB+amp plates for $30 \mathrm{~min}$ at $37^{\circ} \mathrm{C}$. Plated transformations were incubated at $37^{\circ} \mathrm{C}$ overnight and the blue and white colonies were counted the next day.

Though low numbers of blue and white colonies were observed after the transformation, at least one blue and one white colony of all plates were picked and replated, if possible, on new sets of $L B+a m p$ plates $(100 \mu \mathrm{g} / \mathrm{ml})$ that were left to incubate overnight at $37^{\circ} \mathrm{C}$. A PCR screen using the aforementioned PCR protocol was performed to ensure the transformed cells that were replated actually contained the hCG gene ligated into the pTargeT vector. The replated samples were then grown up in $3 \mathrm{ml}$ of liquid LB media with ampicillin $(50 \mathrm{mg} / \mathrm{ml})$ at $37^{\circ} \mathrm{C}$ for $\sim 6$ hours with shaking (250rpm). The pTargeT vector containing the hCG gene was isolated using a QIAfilter Plasmid Purification Maxi Kit (QIAGEN) and was resuspended in $60 \mu \mathrm{l}$ $10 \mathrm{mM}$ Tris-Cl, $\mathrm{pH} 8.5$, to yield a vector DNA concentration of $4.433 \mu \mathrm{g} / \mu \mathrm{l}$.

\section{Transfection}

HeLa cells were cultured in preparation for the transfection with the pTargeT vector with the hCG gene of interest. The cells were grown in a T-75 flask and then were to be transferred into 6-well plates for further growth and eventual transfection. Existing HeLa media (89\% RPMI 1640, 10\% heat-inactivated FBS, 1\% $200 \mathrm{mM}$ L-Glutamine) was removed from cells and $3 \mathrm{ml}$ of trypsin was added to release adherent cells from the sides of the container. After incubating for $3 \mathrm{~min}$ at $37^{\circ} \mathrm{C}, 5 \% \mathrm{CO}_{2}$, the flask was tapped to loosen the cells and $3 \mathrm{ml}$ of warm HeLa media was added to the cells. Cell counts were determined by using a hemocytometer after adding Trypan Blue to an aliquot of the cell culture to mark all dead cells. The $6 \mathrm{ml}$ of cells and media were transferred from the flask to a falcon tube, spun at $1,000 \mathrm{rpm}$ for $5 \mathrm{~min}$, and the pelleted cells were resuspended in media to a desirable concentration.

Prior to transfection, $1 \times 10^{6} \mathrm{HeLa}$ cells were plated in antibiotic-free media 24 hours in advance so as to achieve maximum confluence. Transfection was carried out using the Lipofectamine 2000 reagent (Invitrogen, Carlsbad, CA) and 10 $\mu$ g total of pTargeT vector with the desired hCG gene insert within each well of cells to be transfected. [reference Alice Chen's paper \& transfection protocol] Cells were incubated at $37^{\circ} \mathrm{C}, 5 \% \mathrm{CO}_{2}$ for various lengths of time, with hCG protein expression being measured both qualitatively and quantitatively by means of pregnancy test strips (First Response) and an hCG-specific ELISA (Abazyme, Needham, MA), respectively. 